\title{
Article
}

\section{Hypertensive disorders of pregnancy and future health and mortality: a record linkage study}

Bhattacharya, Sohinee, Prescott, Gordon, Iversen, Lisa, Campbell, Doris, Smith, William Cairns Stewart and Hannaford, Philip Christopher

Available at http://clok.uclan.ac.uk/25041/

Bhattacharya, Sohinee, Prescott, Gordon ORCID: 0000-0002-9156-2361, Iversen, Lisa, Campbell, Doris, Smith, William Cairns Stewart and Hannaford, Philip Christopher (2012) Hypertensive disorders of pregnancy and future health and mortality: a record linkage study. Pregnancy Hypertension: An International Journal of Women's Cardiovascular Health, 2 (1). pp. 1-7. ISSN 2210-7789

It is advisable to refer to the publisher's version if you intend to cite from the work. http://dx.doi.org/10.1016/j.preghy.2011.08.116

For more information about UCLan's research in this area go to http://www.uclan.ac.uk/researchgroups/ and search for < name of research Group>.

For information about Research generally at UCLan please go to http://www.uclan.ac.uk/research/

All outputs in CLoK are protected by Intellectual Property Rights law, including Copyright law. Copyright, IPR and Moral Rights for the works on this site are retained by the individual authors and/or other copyright owners. Terms and conditions for use of this material are defined in the policies page.

\section{CLoK}

Central Lancashire online Knowledge www.clok.uclan.ac.uk

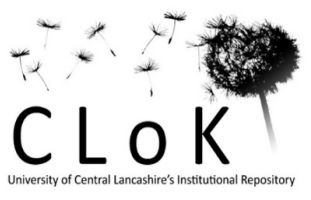


Hypertensive disorders of pregnancy and future health and mortality: a record linkage study

S Bhattacharya ${ }^{1}$, G J Prescott ${ }^{1}$, L Iversen², D M Campbell ${ }^{3}$, WCS Smith ${ }^{1}$, PC Hannaford ${ }^{2}$

${ }^{1}$ Section of Population Health, School of Medicine and Dentistry, University of Aberdeen

${ }^{2}$ Centre of Academic Primary Care, School of Medicine and Dentistry, University of Aberdeen, Foresterhill Health Centre, Westburn Road, Aberdeen AB25 2AY.

${ }^{3}$ Obstetrics and Gynaecology, Aberdeen Maternity Hospital, AB25 2ZL

Correspondence to:

Sohinee Bhattacharya, Dugald Baird Centre for Research on Women's Health, Aberdeen Maternity Hospital, AB25 2ZL, Aberdeen, Scotland

Tel: $+44(0) 1224554672$

e-mail: sohinee.bhattacharya@abdn.ac.uk

Running Title: Hypertensive disorders of pregnancy and future health and mortality

Acknowledgements: We would like to thank Linda Murdoch for identifying the cohort and extracting data from the Aberdeen Maternity and Neonatal Databank and Richard Dobbie for carrying out the data linkage and extraction from the SMR and GRO-S databases.

\section{Ethical considerations}

The analyses were conducted on the anonymised linked dataset. Consequently, formal research ethics committee approval was not required. Approval was obtained from the Caldicott Guardian of the AMND (its Steering Committee) and the Privacy Advisory Committee of ISD. 


\section{Abstract}

The objective of this register-based cohort study was to examine the relationship between hypertensive disorders of pregnancy and future hospital discharges from specified causes including cardiovascular disease, incident cancer registrations and mortality. From the Aberdeen Maternity and Neonatal Databank we identified 34,854 women who were born on or before $31^{\text {st }}$ December 1967 and who had (i) preeclampsia/eclampsia, (ii) gestational hypertension or (iii) normal blood pressure in their first pregnancy. Hospital discharges from selected causes including cardiovascular disease, cancer registrations and deaths in these women were identified from the Scottish Morbidity Records.

There were 2,026 women who had preeclampsia, 8,891 who had gestational hypertension and 23,937 who were normotensive during their first pregnancy. Compared to normotensive women, women with preeclampsia had a higher mortality from ischaemic heart disease (adj. IRR 1.38, 95\% Cl 1.03, 1.84) and circulatory disease (adj. IRR 1.30, 95\% CI 1.06, 1.60). Similar trends were seen with gestational hypertension. There was no difference in all cause mortality in the three groups. The odds of a hypertensive episode were higher in women with preeclampsia (adj. OR $1.79,95 \% \mathrm{Cl} 1.55,2.05)$ and gestational hypertension (adj. OR 1.68, 95\% Cl 1.55, 1.82) compared to normotensives. Compared to normotensives, women with gestational hypertension (adj. IRR $0.91,95 \% \mathrm{Cl} 0.85,0.96$ ) or preeclampsia (adj. IRR $0.86,95 \% \mathrm{Cl} 0.77,0.97)$ had lower incidences of cancer.

Women with pregnancy induced hypertension are at a higher risk of incidence and mortality from ischaemic heart disease and a lower risk of cancer.

Key words: preeclampsia, gestational hypertension, mortality, cancer, cardiovascular disease 


\section{Introduction:}

Historically, hypertensive disorders of pregnancy were believed to be self limiting, with minimal residual effects on health once the pregnancy had ended. However, several primary studies ${ }^{1-5}$ and two meta-analyses ${ }^{6,7}$ have shown that hypertensive problems in pregnancy - including gestational hypertension, toxaemia of pregnancy (the term previously used for what is now called preeclampsia), preeclampsia and/or eclampsia may be associated with an increased risk of hypertension, ischaemic heart disease and stroke later in life. Several studies have also examined future mortality risk, with conflicting results ${ }^{8-10}$. Conflicting results have also been reported regarding the risk of cancer in women with preeclampsia ${ }^{11,12}$. Between 1996 and 1999, the Aberdeen Study of Cardiovascular Disease in Women (ASCHW) explored the subsequent cardiovascular health of 3593 women who had pre-eclampsia/eclampsia; gestational hypertension or normotension during their first pregnancy which ended with a live singleton birth between 1951 and $1970^{3}$.

Cardiovascular health was assessed using a postal questionnaire, clinical examination and linkage to hospital discharge and mortality data. Compared to women with a normotensive first pregnancy, those with gestational hypertension or preeclampsia/eclampsia were more likely to have subsequent hypertension; preeclamptic/eclamptic women also had higher rates of hospital admission for, and deaths from, cerebrovascular disease. At the time of the study the number of cardiovascular events was relatively small. In this paper, we examine the relationship between hypertensive disorders of pregnancy and future risk of hospital discharge for selected conditions, cancer and death using the expanded ASCHW cohort who are now older and therefore likely to have more outcome events. 


\section{Methods}

\section{Identification of cohort}

The Aberdeen Maternity and Neonatal Databank (AMND) has contemporaneously recorded and stored information on all pregnancy related events occurring in Aberdeen from 1950 to the present day. Standardised coding criteria are used to define and record hypertensive disorders of pregnancy in the AMND ${ }^{13}$. From the AMND we identified all women who were born before 1968 and who were living in Aberdeen City and District at the time of their first pregnancy. Women who had pregnancy induced hypertension (either gestational hypertension or preeclampsia/eclampsia) in their first pregnancy formed the exposed groups. All women who were normotensive in their first pregnancy formed the unexposed, comparison group. Gestational hypertension was defined as diastolic pressure $>90 \mathrm{~mm} \mathrm{Hg}$ on two occasions at least four hours apart or a single reading of $>110 \mathrm{~mm} \mathrm{Hg}$; from 20 weeks gestation onwards in a previously normotensive woman. Pre-eclampsia was defined as gestational hypertension plus at least one episode of proteinuria of 0.3 g/24 hours. Eclampsia was defined clinically as convulsions occurring in the presence of pre-eclampsia. In this paper women with pre-eclampsia and those with eclampsia were considered together as one group. Women with chronic hypertension diagnosed at the first antenatal booking visit are identified separately in the AMND, and were excluded from this study. Women who had twins or other multiple gestations were also excluded.

\section{Data linkage}

The Information and Statistics Division (ISD) of the NHS National Services, Scotland linked the AMND records with details of all subsequent hospital discharges (Scottish Morbidity Record, SMR01), cancer registrations (SMR06) and death registrations (General Register Office for Scotland, GRO-S) occurring in members of the cohort. ISD holds relevant morbidity and mortality data for all individuals who have ever been resident in Scotland. The cancer registry has been collecting information on all new 
cases of cancer in Scotland since 1958. The Scottish Morbidity Records have reliable information on all hospital discharges since 1980. Information was available at the time of data linkage about cancer registrations up to $31^{\text {st }}$ January 2007 , hospital discharges to $31^{\text {st }}$ December 2007 and deaths to $31^{\text {st }}$ March 2008. The data linkage process used probability matching based on first name, surname, previous surname and date of birth. Any obvious mismatches were checked manually by ISD data analysts. After ISD had linked the AMND records with their data, all personal identifying information was removed before the linked dataset was released to us.

Outcome events were coded by ISD or GRO-S, using the International Classification of Disease (ICD) $9^{\text {th }}$ revision until April 1996, and the $10^{\text {th }}$ revision thereafter. Outcomes were categorised as: hypertension (ICD-9: 401-4; ICD-10: I10-4); ischaemic heart disease $(410-4,428$; $120-5,150)$; cerebrovascular disease (430-8; I60-9); kidney disease (580-99; N00-39); other circulatory disease (390-8, 405, 41527, 440-59; I00-9, I15, I26-8, I30-49, I51-2, I70-99), all circulatory disease (390-459; I00-I99, G45). The site of cancer were recorded as ICD-9 codes (140-239) and/ or ICD-10 (Any C or D categories).

\section{Statistical analysis}

We used chi square and t tests as appropriate to test for baseline differences among the three groups of women. For all analyses, we used the normotensive group as the referent group. Mortality differences between groups were examined by calculating unadjusted and adjusted incident rate ratios (IRRs) using Poisson regression in STATA version 11(Stata Corp., Texas, USA). Adjustments were made for: year of birth, smoking status and social class of the women at the time of their first pregnancy. For many women, smoking behaviour at time of booking was not recorded. Smoking status was included in the models as yes, no and unknown status, to avoid excluding a large number of women from the analyses. Key analyses were repeated excluding any women with unknown smoking status. Social class has been 
coded in the AMND according to the British Registrar General's occupational social class classification of 1951: I- professional, II- managerial, Illa- skilled non-manual, IIlb- skilled manual, IV-semi-skilled, V- unskilled ${ }^{14}$. This is allocated on the basis of the partner's social class if available or the woman's own social class if she has no partner.

This Poisson regression approach was also used when examining the cancer registrations, since the date of first cancer registration was known. We excluded women who had a date of first cancer registration prior to delivery and women who had their delivery date after the final follow-up date for our extraction from the cancer register (31 st January 2007).

Hospital discharge data held by ISD do not indicate whether the episode was the first event. Since we did not have an accurate date of first diagnosis, incidence rate ratios could not be calculated for the hospital discharge data. Instead we used logistic regression to calculate odds ratios for the presence of specific hospital discharges, unadjusted and adjusted for potential confounding by women's year of birth, smoking status and social class at time of first pregnancy.

\section{Results:}

We identified from the AMND 46929 women with year of birth before 1968 who were resident in Aberdeen City and District at the time of their first pregnancy leading to delivery. Women with twins or other multiple pregnancies were excluded. Of these, 174 women with chronic hypertension were excluded from the analysis. After excluding duplicate cases $(n=128), 74.8 \%$ of the women were linked to one or more of SMR01, SMR06 and GRO-S. One woman with death registered prior to delivery was excluded from the analysis as an incorrect match. After the various exclusions, there were 23,937 normotensive women, 8,891 women who had gestational hypertension and 2,026 women who had had pre-eclampsia or eclampsia in their first pregnancy; all of whom were linked to at least one register. Follow up started from the 
year of delivery recorded in the AMND. Follow up for death was 1,200,910 woman years and that for cancer registration was 1,109,329 woman years.

Table 1 presents the baseline characteristics of the women in the exposed and unexposed groups at the time of their first pregnancy. Compared to women who were normotensive in their first pregnancy, women with gestational hypertension or preeclampsia/eclampsia were more likely to have a body mass index (BMI) over 30 $\mathrm{kg} / \mathrm{m}^{2}$, but were less likely to be smokers. There were no statistically significant differences between the three groups in terms of mean age at first delivery, social class and marital status.

Table 2 shows the number and proportion of deaths occurring in the three groups. The mean (standard deviation) age of death in the normotensive, gestational hypertension and preeclampsia groups was 64.3 (11.7), 63.9 (12.6) and 64.0 (12.4) years respectively. The death rates per 10,000 woman-years of follow-up were 40.2, 37.6 and 38.8, respectively. Compared to women who were normotensive in their first pregnancy, women with gestational hypertension had lower rates of death from any cancer, breast and respiratory system cancer, although the IRRs did not remain statistically significant after adjusting for smoking, social class and year of birth. Women with gestational hypertension also had a higher risk of death from cerebrovascular disease adjusted incident rate ratio (adj. IRR) 1.28, 95\% confidence interval $(\mathrm{Cl}) 1.03,1.59\}$, ischaemic heart disease (adj. IRR 1.35, 95\% Cl 1.15, 1.59), and all circulatory diseases (adj. IRR 1.25, 95\% Cl 1.11, 1.41); and a lower risk of death from non-cancerous respiratory disease (adj. IRR 0.76, 95\% CI 0.60, 0.97). Compared to normotensive women, women with pre-eclampsia/eclampsia had a higher mortality rate from ischaemic heart disease (adj. IRR 1.38, 95\% CI 1.03, 1.84) and all circulatory diseases (adj. IRR $1.30,95 \% \mathrm{Cl} \mathrm{1.06,1.60).} \mathrm{None} \mathrm{of} \mathrm{the} \mathrm{incident}$ rate ratios for the other mortality outcomes were statistically significant. Table 3 presents the chances of having at least one hospital episode due to selected conditions in the three groups of women. This table shows the counts of women in 
each group with at least one admission of the specific type as defined by the discharge diagnosis. A woman with at least one admission for hypertension and at least one admission for cerebrovascular disease would be counted in both of the appropriate discharge diagnosis rows, as well as once in the all circulatory row. Compared with normotensive women, those with gestational hypertension were more likely to be hospitalised because of any circulatory disease (adjusted odds ratio (adj. OR) $1.22,95 \% \mathrm{Cl} 1.15,1.29)$, hypertension (adj. OR 1.68, 95\% $\mathrm{Cl} 1.55,1.82)$, and ischaemic heart disease (adj. OR 1.22, 95\% Cl 1.11, 1.34). The adjusted odds ratios of hospital discharge from any circulatory disease (adj. OR 1.20, 95\% Cl 1.08, 1.33) and hypertension (adj. OR 1.79, 95\% Cl 1.55, 2.05) were significantly higher in women with pre-eclampsia/eclampsia, when compared to normotensive women. The mean (standard deviation) age at first cancer registration in the normotensive, gestational hypertension and preeclampsia groups were 52.4 (14.9), 51.8 (14.5) and 51.6 (15.0) years respectively. The rates of cancer registration per 10,000 womanyears of follow-up were 58.5, 52.1 and 48.9 , respectively. Women with gestational hypertension had a lower rate of any cancer registration compared to normotensive women (adj. IRR 0.91, 95\% Cl 0.85, 0.96); as did women with preeclampsia/exclampsia (adj. IRR 0.86, 95\% CI 0.77, 0.97; Table 4). In addition, women with gestational hypertension had a lower rate of cancer of the respiratory system (adj. IRR $0.79,95 \% \mathrm{Cl} 0.63,0.99$ ) and other cancers not specified (which included carcinoma-in-situ of the uterine cervix - adj. IRR 0.88, 95\% CI 0.81, 0.95). When key analyses were repeated excluding women with unknown smoking status, the risk estimates were broadly similar in size and direction (tables available on request).

\section{Discussion:}


We found that women with gestational hypertension or preeclampsia/eclampsia in their first pregnancy were more likely to be discharged from hospital with, and have higher death rates from, ischaemic heart disease and all circulatory disease (including ischaemic heart disease and cerebrovascular disease) than normotensive women. Women with hypertensive disorders of pregnancy were also more likely to have at least one hospital discharge, but not mortality, from hypertensive disorders later in life. There was an overall reduced risk of cancer registration in women with gestational hypertension or preeclampsia/eclampsia in their first pregnancy and a non-significant lower risk of cancer mortality. We did not find an association between hypertensive diseases of pregnancy and all cause mortality.

The association between preeclampsia/eclampsia and the future cardiovascular health of women is now well established. In the first of the two meta-analyses, Bellamy et al ${ }^{6}$ found that the pooled relative risk of ischaemic heart disease in women with a history of preeclampsia was $2.16(95 \% \mathrm{Cl} 1.86,2.52)$, hypertension in later life was $3.70(95 \% \mathrm{Cl} 2.70,5.05)$ and fatal and non-fatal stroke was $1.81(95 \%$ Cl 1.45, 2.27). McDonald et al ${ }^{7}$ found a similar doubling of risk of overall cardiovascular disease in women with a history of preeclampsia. Our study supports most of the increased cardiovascular risks with preeclampsia/eclampsia found in the other studies, although we did not find a statistically significant relationship with fatal or non-fatal cerebrovascular events. We also found an increased risk in subsequent cardiovascular disease in women with gestational hypertension. In the original ASCHW study ${ }^{3}$, we observed an increase in risk of hypertension and stroke in later life but not admission to hospital, or death, from ischaemic heart disease. Lykke et $\mathrm{al}^{15}$ reported a more than a five-fold increase in the risk of subsequent hypertension after gestational hypertension.

Several studies have analysed the risk of all cause mortality and mortality from cardiovascular disease in women with hypertensive disorders of pregnancy and reported conflicting results. Jonsdottir et al ${ }^{8}$ found a dose dependent increase in risk 
of death in women with gestational hypertension, preeclampsia and eclampsia compared to women who were normotensive in pregnancy. Almost half of the excess risk was attributable to cardiovascular mortality. Using population based Scottish data; Smith et $\mathrm{al}^{2}$ reported the additive effects of preeclampsia, preterm delivery and delivery of small for date babies on hospital admissions and mortality from ischaemic heart disease. More recently, Iversen and Hannaford ${ }^{10}$ found a significantly higher risk of all cause mortality and mortality from vascular conditions in women with toxaemia of pregnancy - the old nomenclature used to describe hypertensive disorders of pregnancy. We found a significantly higher risk of cardiovascular mortality in women with preeclampsia and gestational hypertension but no difference in all cause mortality. It is possible that the excess risk of cardiovascular mortality in these women may have been offset by the slight reduction in risk of cancer mortality and death from non-cancerous respiratory diseases.

The relationship between preeclampsia or gestational hypertension and the risk of subsequent cancer has received less attention than for cardiovascular outcomes, and the literature is less consistent. Similar to our findings, others have also failed to find a significant relationship between preeclampsia and future risk of maternal death from cancer $^{9,20}$. A cohort study of women living in Utah, USA found that preeclampsia was associated with a statistically significant reduced risk of any cancer later in life (hazard ratio: $0.92,95 \% \mathrm{Cl} 0.85$ to 0.99$){ }^{11}$. Conversely, an Israeli cohort study found an overall increased risk of cancer incidence following preeclampsia ${ }^{12}{ }^{19}$, mainly due to an increased risk of cancers of the breast and ovary ${ }^{12}$. While some studies report a reducedrisk ${ }^{11,16}$ of breast cancer others have found no such association ${ }^{9,17-20}$. In their meta-analysis, Bellamy et al ${ }^{6}$ did not find any association between preeclampsia and the risk of cancer, overall or for specific sites.

We report the findings from a large historical cohort study of women's health following pregnancy and delivery. Following on from our original work ${ }^{3}$, this new analysis benefited from a tenfold increase in the size of the cohort and an increase of 
at least 10 years' follow up. A study on such a large scale was made feasible by the record linkage of routinely collected data, rather than a de novo study. The contemporaneous recording of data in both the AMND and the SMR databases reduces the potential for recall bias. Both databases are subject to quality control measures, enabling us to be confident in both the exposure and outcome variables. Apart from our previous report from the original ASCHW cohort, ${ }^{3}$ which was based on smaller numbers, this is, to our knowledge, the only other primary study to take such a comprehensive approach.

The study, however, has limitations which are partly due to the nature of the record linkage process. Only $74 \%$ of the cohort identified from the AMND was matched with the SMR databases. The remainder may have left Scotland or remained alive with no health events requiring a hospital admission or cancer registration. We cannot rule out selection bias resulting from this. However, the women whose AMND records could not be matched with the SMR database were evenly distributed across the three groups of women being compared, suggesting minimal bias (tables available on request). Moreover, the probability matching technique used for linkage of records is subject to at least $3 \%$ error in either direction. We were only able to adjust for the potential confounding factors of year of birth, social class and smoking. In addition, smoking data were missing for a number of women. Our findings, therefore, may be influenced by residual confounding especially by BMI. Lastly, we were only able to assess outcomes that warranted hospital admissions, thereby missing asymptomatic cases, and cases managed exclusively in the community. This is likely to have greatest impact on outcomes like chronic hypertension, where most cases are managed in the community.

Despite these limitations, our results suggest an increased risk of fatal and non-fatal cardiovascular disease among women who have had a hypertensive problem in pregnancy. The mechanisms by which such effects occur remain elusive.

Controversy remains about whether the effects occur because pregnancy unmasks a 
predisposition to vascular disease (i.e. pregnancy is a risk marker of vascular disease) and/or whether hypertensive disorders in pregnancy cause permanent damage to the vascular system (i.e. they are risk factors for cardiovascular disease $)^{21}$.

In addition to wanting to know the cause underlying the association between hypertensive disorders in pregnancy and cardiovascular risk, clinicians and their patients are likely to want to know when the risk first appears, and what can be done about it. More work is needed to identify the timing of risk increase. Until this is identified, women with a history of hypertensive problems in pregnancy should be informed that they have an increased risk of cardiovascular disease later in life and that they should follow current advice for good cardiovascular health (i.e. do not smoke, drink in moderation, avoid being overweight, be active and eat a healthy diet). Although some authorities recommend that all women who have had a hypertensive disorder in pregnancy should have their blood pressure measured ${ }^{22}$, other guidelines suggest that, in the absence of indicators of high cardiovascular risk (e.g. a previous cardiovascular event, history of diabetes or familial hypercholesterolaemia), all adults aged 40 and older should have their cardiovascular risk assessed every five years ${ }^{23}$. As a minimum, women with a history of a hypertensive problem in pregnancy should be strongly encouraged to take part in such screening.

\section{Conclusions:}

Our results indicate that women with a history of gestational hypertension or preeclampsia/eclampsia have an increased risk of hospital discharge for, and mortality from, all circulatory disease, as well as some specific cardiovascular events; and a reduced risk of being registered as having had cancer later in life. No relationship was apparent between pregnancy induced hypertension and all cause mortality. 


\section{References}

1. Hannaford P, Ferry S, Hirsch S. Cardiovascular sequelae of toxaemia of pregnancy. Heart 1997;77(2):154-8.

2. Smith GCS, Pell JP, Walsh D. Pregnancy complications and maternal risk of ischaemic heart disease: A retrospective cohort study of 129290 births. Lancet $2001 ; 357(9273): 2002-6$.

3. Wilson BJ, Watson MS, Prescott GJ, Sunderland S, Campbell DM, Hannaford P, et al. Hypertensive diseases of pregnancy and risk of hypertension and stroke in later life: Results from cohort study. Br Med J 2003;326(7394):845-9.

4. Wikström A-, Haglund B, Olovsson M, Lindeberg SN. The risk of maternal ischaemic heart disease after gestational hypertensive disease. BJOG: An International Journal of Obstetrics and Gynaecology 2005;112(11):1486-91.

5. Roberts JM, Gammill H. Pre-eclampsia and cardiovascular disease in later life. Lancet 2005;366(9490):961-2.

6. Bellamy L, Casas J-, Hingorani AD, Williams DJ. Pre-eclampsia and risk of cardiovascular disease and cancer in later life: Systematic review and meta-analysis. Br Med J 2007;335(7627):974-7.

7. McDonald SD, Malinowski A, Zhou Q, Yusuf S, Devereaux PJ. Cardiovascular sequelae of preeclampsia/eclampsia: A systematic review and meta-analyses. $A m$ Heart J 2008;156(5):918-30.

8. Jonsdottir LS, Arngrimsson R, Geirsson RT, Sigvaldason H, Sigfusson N. Death rates from ischemic heart disease in women with a history of hypertension in pregnancy. Acta Obstet Gynecol Scand 1995; Nov;74(10):772-6. 
9. Funai EF, Friedlander Y, Paltiel O, Tiram E, Xue X, Deutsch L, et al. Long-term mortality after preeclampsia. Epidemiology 2005;16(2):206-15.

10. Iversen L, Hannaford PC. Toxaemia of pregnancy and risk of mortality in later life: Evidence from the royal college of general practitioners' oral contraception study. Hypertension in Pregnancy 2010;29(2):180-97.

11. Aagaard-Tillery KM, Stoddard GJ, Holmgren C, Lacoursiere DY, Fraser A, Mineau GP, et al. Preeclampsia and subsequent risk of cancer in Utah. Obstet Gynecol 2006;195(3):691-9.

12. Calderon-Margalit R, Friedlander Y, Yanetz R, Deutsch L, Perrin MC, Kleinhaus $\mathrm{K}$, et al. Preeclampsia and subsequent risk of cancer: update from the Jerusalem Perinatal Study. Obstet Gynecol 2009;200(1):63.e1,63.e5.

13. Davey DA, MacGillivray I. The classification and definition of the hypertensive disorders of pregnancy. American Journal of Obstetrics \& Gynecology 1988; Apr;158(4):892-8.

14. Office for National Statistics. Standard Occupational Classification. HMSO; 2000.

15. Lykke JA, Langhoff-Roos J, Sibai BM, Funai EF, Triche EW, Paidas MJ. Hypertensive pregnancy disorders and subsequent cardiovascular morbidity and type 2 diabetes mellitus in the mother. Hypertension 2009;53(6):944-51.

16. Vatten LJ, Romundstad PR, Trichopoulos D, Skjærven R. Pre-eclampsia in pregnancy and subsequent risk for breast cancer. Br J Cancer 2002;87(9):971-3.

17. Cohn BA, Cirillo PM, Christianson RE, Van Den Berg BJ, Siiteri PK. Placental characteristics and reduced risk of maternal breast cancer. J Natl Cancer Inst $2001 ; 93(15): 1133-40$. 
18. Mogren I, Stenlund H, Högberg U. Long-term impact of reproductive factors on the risk of cervical, endometrial, ovarian and breast cancer. Acta Oncol $2001 ; 40(7): 849-54$.

19. Paltiel O, Friedlander Y, Tiram E, Barchana M, Xue X, Harlap S. Cancer after preeclampsia: Follow up of the Jerusalem perinatal study cohort. $\mathrm{Br}$ Med J $2004 ; 328(7445): 919-21$.

20. Irgens HU, Reisaeter L, Irgens LM, Lie RT. Long term mortality of mothers and fathers after pre-eclampsia: Population based cohort study. Br Med J 2001; 24 NOV $2001 ; 323(7323): 1213-6$.

21. Sattar N. Do pregnancy complications and CVD share common antecedents?. Atherosclerosis Supplements 2004;5(2):3-7.

22. Williams B, Poulter NR, Brown MJ, Davis M, McInnes GT, Potter JF, et al. Guidelines for management of hypertension: Report of the fourth working party of the Bristish Hypertension Society, 2004 - BHS IV. J Hum Hypertens 2004;18(3):139-85.

23. Risk estimation and the prevention of cardiovascular disease. A national clinical guideline. Accessed August 16, 2010. 
Table 1. Baseline characteristics of study cohort at antenatal booking unless stated otherwise

\begin{tabular}{|c|c|c|c|c|}
\hline & Normotensive & $\begin{array}{c}\text { Gestational } \\
\text { hypertension }\end{array}$ & $\begin{array}{l}\text { Preeclampsia/ } \\
\text { eclampsia }\end{array}$ & p-value \\
\hline Total & $23,937(68.4 \%)$ & $8,891(25.4 \%)$ & $2,026(5.8 \%)$ & \\
\hline $\begin{array}{l}\text { Mean (SD) age at } 1^{\text {st }} \\
\text { delivery (years) }\end{array}$ & $24.25(4.94)$ & $24.34(4.84)$ & $24.57(5.10)$ & 0.13 \\
\hline $\begin{array}{l}\text { No(\%) BMI categories* } \\
\left(\mathrm{kg} / \mathrm{m}^{2}\right)\end{array}$ & & & & 0.01 \\
\hline$<20$ & $1,356(5.7 \%)$ & $330(3.7 \%)$ & $67(3.3 \%)$ & \\
\hline $20-24.99$ & $6,944(29.0 \%)$ & $2,424(27.3 \%)$ & $536(26.5 \%)$ & \\
\hline $25-29.99$ & $2,114(8.8 \%)$ & $1,259(14.2 \%)$ & $277(13.7 \%)$ & \\
\hline $30-34.99$ & $308(1.3 \%)$ & $292(3.3 \%)$ & $73(3.6 \%)$ & \\
\hline$>35$ & $79(0.3 \%)$ & $101(1.1 \%)$ & 31 (1.5\%) & \\
\hline Missing & $13,136(54.9 \%)$ & $4,485(50.4 \%)$ & $1,042(51.4 \%)$ & \\
\hline $\begin{array}{l}\text { No }(\%) \text { in social class } \\
\text { non-manual }\end{array}$ & $6,512(27.2 \%)$ & $2,451(27.6 \%)$ & $534(26.4 \%)$ & 0.49 \\
\hline $\begin{array}{l}\text { No }(\%) \text { in social class } \\
\text { manual }\end{array}$ & $12,744(53.2 \%)$ & $4,507(50.7 \%)$ & $1,033(51.0 \%)$ & \\
\hline Missing social class & $4,681(19.6 \%)$ & $1,933(21.7 \%)$ & $459(22.7 \%)$ & \\
\hline $\begin{array}{l}\text { No (\%) who had ever } \\
\text { smoked* }^{*}\end{array}$ & $6,036(25.2 \%)$ & $2,048(23.0 \%)$ & $385(19.0 \%)$ & $<0.01$ \\
\hline No (\%) never smoked & $9,115(38.1 \%)$ & $4,135(46.5 \%)$ & 1,032 (50.9\%) & \\
\hline Missing smoking & $8,786(36.7 \%)$ & $2,708(30.5 \%)$ & $609(30.1 \%)$ & \\
\hline No (\%) single & 2,605 (10.9\%) & $914(10.3 \%)$ & $212(10.5 \%)$ & 0.43 \\
\hline $\begin{array}{l}\text { No }(\%) \text { married/living } \\
\text { as married }\end{array}$ & $21,322(89.1 \%)$ & $7,974(89.7 \%)$ & $1,812(89.4 \%)$ & \\
\hline Missing marital status & $10(0 \%)$ & $3(0 \%)$ & $2(0.2 \%)$ & \\
\hline
\end{tabular}


Table 2. Unadjusted and adjusted incident rate ratios for all- and cause-specific mortality in all traced women; normotensive women as reference group

Gestational hypertension $(n=8,891)$

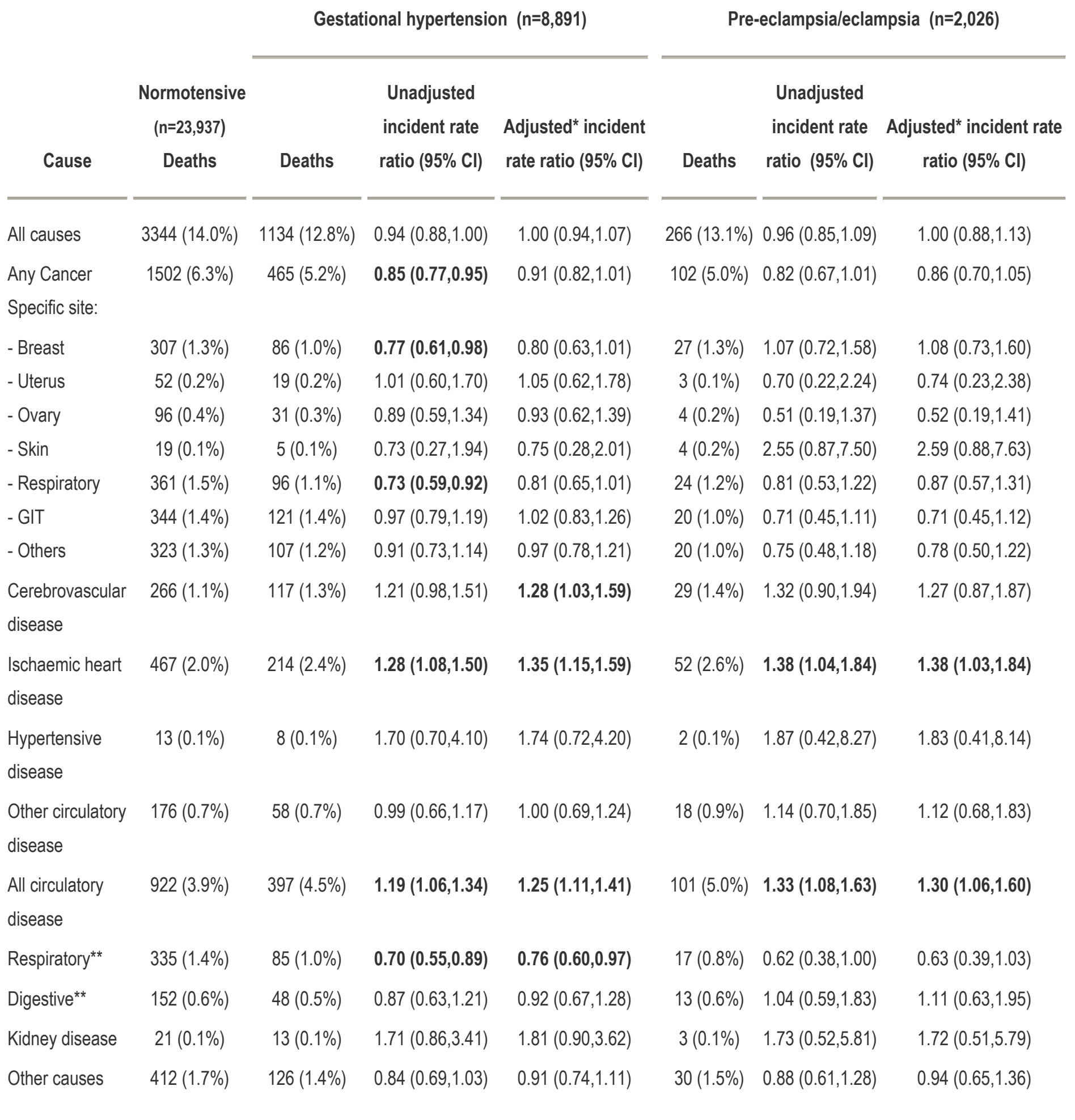

*Adjusted for year of birth, social class and smoking. ** Excluding cancer

Statistically significant incident rate ratios are shown in bold

Pre-eclampsia/eclampsia $(n=2,026)$ 
Table 3. Unadjusted and adjusted odds ratios $(95 \% \mathrm{Cl})$ of at least one hospital discharge for selected causes; normotensive women as reference group.

\begin{tabular}{|c|c|c|c|c|c|c|c|}
\hline \multirow[b]{2}{*}{ Discharge diagnosis } & \multicolumn{7}{|l|}{$\begin{array}{l}\text { Normotensive } \\
(n=23,937)\end{array}$} \\
\hline & $\begin{array}{l}\text { Hospital } \\
\text { discharges }\end{array}$ & No of discharges & $\begin{array}{l}\text { Unadjusted odds } \\
\text { ratio }(95 \% \mathrm{Cl})\end{array}$ & $\begin{array}{l}\text { Adjusted* odds } \\
\text { ratio }(95 \% \mathrm{Cl})\end{array}$ & No of discharges & $\begin{array}{l}\text { Unadjusted odds } \\
\text { ratio }(95 \% \mathrm{Cl})\end{array}$ & $\begin{array}{c}\text { Adjusted }^{*} \text { odds ratio }(95 \% \\
\mathrm{Cl})\end{array}$ \\
\hline All circulatory & $7273(30.4 \%)$ & 2926 (32.9\%) & $1.12(1.07,1.18)$ & $1.22(1.15,1.29)$ & $662(32.7 \%)$ & $1.11(1.01,1.23)$ & $1.20(1.08,1.33)$ \\
\hline Hypertension & $2260(9.4 \%)$ & $1201(13.5 \%)$ & $1.50(1.39,1.61)$ & $1.68(1.55,1.82)$ & $290(14.3 \%)$ & $1.60(1.41,1.83)$ & $1.79(1.55,2.05)$ \\
\hline $\begin{array}{r}\text { Cerebrovascular } \\
\text { disease }\end{array}$ & $1004(4.2 \%)$ & $361(4.1 \%)$ & $0.97(0.86,1.09)$ & $1.04(0.91,1.18)$ & $94(4.6 \%)$ & $1.11(0.90,1.38)$ & $1.16(0.93,1.45)$ \\
\hline Ischaemic heart disease & $1882(7.9 \%)$ & $756(8.5 \%)$ & $1.09(1.00,1.19)$ & $1.22(1.11,1.34)$ & $172(8.5 \%)$ & $1.09(0.92,1.28)$ & $1.18(0.99,1.41)$ \\
\hline Arterial diseases & $550(2.3 \%)$ & $218(2.5 \%)$ & $1.07(0.91,1.25)$ & $1.16(0.99,1.36)$ & $56(2.8 \%)$ & $1.21(0.92,1.60)$ & $1.28(0.96,1.70)$ \\
\hline Pulmonary embolism & $294(1.2 \%)$ & $90(1.0 \%)$ & $0.82(0.65,1.04)$ & $0.86(0.67,1.09)$ & $23(1.1 \%)$ & $0.92(0.60,1.42)$ & $0.95(0.62,1.45)$ \\
\hline Kidney disease & $741(3.1 \%)$ & $283(3.2 \%)$ & $1.03(0.90,1.18)$ & $1.09(0.95,1.25)$ & $71(3.5 \%)$ & $1.14(0.89,1.46)$ & $1.20(0.93,1.54)$ \\
\hline
\end{tabular}

* Adjusted for year of birth, social class and smoking

Statistically significant odds ratios are shown in bold 
1 Table 4. Unadjusted and adjusted incident rate ratios for first cancer registration in

2 all traced women; normotensive women as reference group

\begin{tabular}{|c|c|c|c|c|c|c|c|}
\hline \multirow[b]{2}{*}{ Cancer } & \multirow{2}{*}{$\begin{array}{l}\text { Normotensive } \\
(\mathrm{n}+=23772) \\
\text { Number of } \\
\text { cancer } \\
\text { registrations }\end{array}$} & \multicolumn{3}{|c|}{$\begin{array}{l}\text { Gestational Hypertension } \\
\qquad(\mathrm{n}+=8852)\end{array}$} & \multicolumn{3}{|c|}{$\begin{array}{l}\text { Pre-eclampsia/eclampsia } \\
\qquad(\mathrm{n}+=2019)\end{array}$} \\
\hline & & $\begin{array}{c}\text { Number of } \\
\text { cancer } \\
\text { registrations }\end{array}$ & $\begin{array}{l}\text { Unadjusted } \\
\text { incident } \\
\text { rate ratio } \\
(95 \% \mathrm{Cl})\end{array}$ & $\begin{array}{l}\text { Adjusted* } \\
\text { incident } \\
\text { rate ratio } \\
(95 \% \mathrm{Cl})\end{array}$ & $\begin{array}{c}\text { Number of } \\
\text { cancer } \\
\text { registrations }\end{array}$ & $\begin{array}{l}\text { Unadjusted } \\
\text { incident } \\
\text { rate ratio } \\
(95 \% \mathrm{Cl})\end{array}$ & $\begin{array}{l}\text { Adjusted } \\
\text { incident } \\
\text { rate ratio } \\
(95 \% \mathrm{Cl})\end{array}$ \\
\hline $\begin{array}{l}\text { All cancers } \\
\text { Specific } \\
\text { site: }\end{array}$ & 4482 (18.9\%) & $1455(16.4 \%)$ & $\begin{array}{c}0.89 \\
(0.84,0.95)\end{array}$ & $\begin{array}{c}0.91 \\
(0.85,0.96)\end{array}$ & $312(15.5 \%)$ & $\begin{array}{c}0.84 \\
(0.75,0.94)\end{array}$ & $\begin{array}{c}0.86 \\
(0.77,0.97)\end{array}$ \\
\hline Breast & 862 (3.6\%) & 292 (3.3\%) & $\begin{array}{c}0.93 \\
(0.81,1.06)\end{array}$ & $\begin{array}{c}0.93 \\
(0.81,1.06)\end{array}$ & 58 (2.9\%) & $\begin{array}{c}0.81 \\
(0.62,1.05)\end{array}$ & $\begin{array}{c}0.80 \\
(0.62,1.05)\end{array}$ \\
\hline Uterus & $183(0.8 \%)$ & $75(0.8 \%)$ & $\begin{array}{c}1.13 \\
(0.86,1.47)\end{array}$ & $\begin{array}{c}1.14 \\
(0.87,1.49)\end{array}$ & $11(0.5 \%)$ & $\begin{array}{c}0.72 \\
(0.39,1.33)\end{array}$ & $\begin{array}{c}0.74 \\
(0.40,1.35)\end{array}$ \\
\hline Ovary & $74(0.3 \%)$ & $23(0.3 \%)$ & $\begin{array}{c}0.85 \\
(0.53,1.36)\end{array}$ & $\begin{array}{c}0.88 \\
(0.55,1.41)\end{array}$ & 7 (0.3\%) & $\begin{array}{c}1.14 \\
(0.52,2.47)\end{array}$ & $\begin{array}{c}1.20 \\
(0.55,2.62)\end{array}$ \\
\hline Skin & 247 (1.0\%) & 82 (0.9\%) & $\begin{array}{c}0.91 \\
(0.71,1.17)\end{array}$ & $\begin{array}{c}0.91 \\
(0.71,1.17)\end{array}$ & $17(0.8 \%)$ & $\begin{array}{c}0.83 \\
(0.51,1.35)\end{array}$ & $\begin{array}{c}0.82 \\
(0.50,1.35)\end{array}$ \\
\hline Respiratory & 363 (1.5\%) & 94 (1.1\%) & $\begin{array}{c}0.71 \\
(0.57,0.89)\end{array}$ & $\begin{array}{c}0.79 \\
(0.63,0.99)\end{array}$ & $22(1.1 \%)$ & $\begin{array}{c}0.73 \\
(0.47,1.12)\end{array}$ & $\begin{array}{c}0.80 \\
(0.52,1.23)\end{array}$ \\
\hline Gl tract & 477 (2.0\%) & $156(1.8 \%)$ & $\begin{array}{c}0.90 \\
(0.75,1.08)\end{array}$ & $\begin{array}{c}0.94 \\
(0.79,1.13)\end{array}$ & $32(1.6 \%)$ & $\begin{array}{c}0.81 \\
(0.56,1.15)\end{array}$ & $\begin{array}{c}0.82 \\
(0.57,1.17)\end{array}$ \\
\hline $\begin{array}{l}\text { Other } \\
\text { cancers }\end{array}$ & 2276 (9.6\%) & 733 (8.3\%) & $\begin{array}{c}0.88 \\
(0.81,0.96)\end{array}$ & $\begin{array}{c}0.88 \\
(0.81,0.95)\end{array}$ & 165 (8.2\%) & $\begin{array}{c}0.87 \\
(0.74,1.02)\end{array}$ & $\begin{array}{c}0.89 \\
(0.76,1.05)\end{array}$ \\
\hline
\end{tabular}

${ }^{\star}$ Adjusted for year of birth, social class and smoking

Statistically significant incident rate ratios are shown in bold

$+\mathrm{n}$ reduced due to exclusion from this analysis of 211 women who had cancer prior to delivery or had a date of delivery after the final date of follow-up from the cancer registry. 